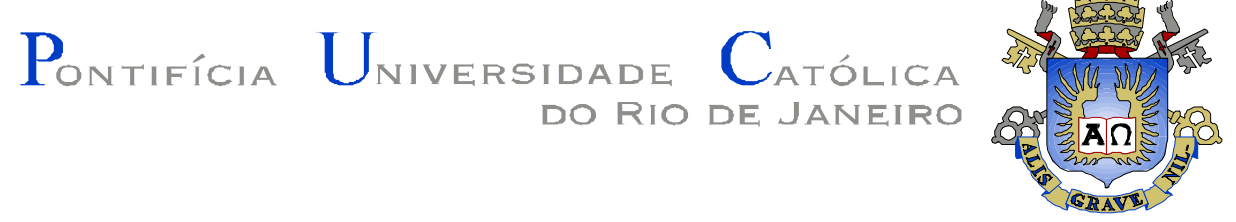

Ramilda Fontan Soto

\title{
A PSICOSSOMÁTICA NA PRIMEIRA INFÂNCIA: \\ A contribuição de Winnicott para um estudo das alergias respiratórias
}

Tese de Doutorado

Tese apresentada ao Programa de Pós-Graduação em Psicologia do Departamento de Psicologia da PUC-Rio como parte dos requisitos para obtenção do título de Doutor em Psicologia.

Orientadora: Cláudia Amorim Garcia

Rio de Janeiro

Fevereiro de 2006 


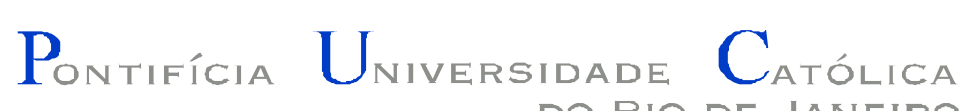

\section{A psicossomática na primeira infância: a contribuição de Winnicott para um estudo das alergias respiratórias.}

Tese apresentada como requisito parcial para obtenção do grau de Doutor pelo Programa de Pós-Graduação em Psicologia Clínica do Departamento de Psicologia do Centro de Teologia e Ciências Humanas da PUC-Rio. Aprovada pela Comissão Examinadora abaixo assinada.

Profa. Cláudia Amorim Garcia Orientadora Departamento de Psicologia - PUC-Rio

Profa. Monah Winograd Departamento de Psicologia - PUC-Rio

Profa. Flávia Sollero de Campos Departamento Psicologia - PUC-Rio

Prof ${ }^{a}$. Maria Stella Tavares Filgueiras

Departamento de Psicologia - UFJF

Prof. Marco Antônio Chagas Guimarães Instituto de Psicossomática

Prof. Paulo Fernando Carneiro de Andrade Coordenador Setorial de Pós-Graduação e Pesquisa do Centro de Teologia e Ciências Humanas - PUC-Rio 
Todos os direitos reservados. É proibida a reprodução total ou parcial do trabalho sem autorização da universidade, da autora e da orientadora.

\section{Ramilda Fontan Soto}

Psicóloga, graduada em 1972, pela Universidade Santa Úrsula. É professora universitária, tendo lecionado no Curso de Psicologia de várias Faculdades, desde 1976. Mestre em Psicologia pela Universidade Federal do Rio de Janeiro, em 1988. Funcionária da Prefeitura da Cidade do Rio de Janeiro, trabalhou na Secretaria de Educação e na Secretaria de Saúde.

Ficha Catalográfica

Soto, Ramilda Fontan

A psicossomática na primeira infância: a contribuição de Winnicott para um estudo das alergias respiratórias / Ramilda Fontan Soto; orientadora: Cláudia Amorim Garcia. - Rio de Janeiro: PUC, Departamento de Psicologia, 2006.

230 f. ; $30 \mathrm{~cm}$

Tese (doutorado) - Pontifícia Universidade Católica do Rio de Janeiro, Departamento de Psicologia.

Inclui referências bibliográficas.

1. Psicologia - Teses. 2. Winnicott. 3. Psicossomática. 4. Infância. 5. Adaptação materna. 6. Alergia respiratória. I. Garcia, Cláudia Amorim. II. Pontifícia Universidade Católica do Rio de Janeiro. Departamento de Psicologia. III. Título. 


\section{Agradecimentos}

À professora Cláudia Amorim Garcia pela compreensão e competência, que foram fundamentais para a realização desse trabalho.

À Dra. Fátima Emerson e Dra. Neide Pereira pela acolhida, e pelas trocas que enriqueceram meu estudo sobre as patologias alérgicas na infância.

À professora Ângela Baraf Podkameni pelo incentivo, e pela generosidade com que guiou meus passos no terreno da psicossomática.

Às mães que, ao me confiarem suas histórias e as de seus filhos, forneceram dados importantes para que a pesquisa pudesse ser desenvolvida.

À Verinha, Marise e Marcelina, pela ajuda sempre carinhosa.

A todos os amigos pela confiança em mim depositada.

Aos meus pais (in memorian). 


\section{Resumo}

Soto, Ramilda Fontan; Garcia, Cláudia Amorim. A psicossomática na primeira infância: a contribuição de Winnicott para um estudo das alergias respiratórias. Rio de Janeiro, 2006. 230p. Tese de Doutorado Departamento de Psicologia, Pontifícia Universidade Católica do Rio de Janeiro.

O objetivo da presente tese foi contribuir para a compreensão das manifestações psicossomáticas na infância, exemplificadas por meio dos distúrbios alérgicos respiratórios. A teoria de Winnicott sobre o desenvolvimento emocional primitivo foi utilizada como principal ferramenta teórica. Foram discutidas as contribuições dos autores identificados com a psicossomática psicanalítica, desde o modelo teórico de Pierre Marty até à literatura relativa a infância, e também os conceitos de Winnicott sobre a relação mãe-bebê. A pesquisa utilizou o conceito winnicottiano de preocupação materna primária, focalizando a adaptação ativa materna, e revelou a existência de uma relação entre as falhas adaptativas maternas e a manifestação psicossomática alérgica da criança.

\section{Palavras-chave:}

Winnicott; Psicossomática; Infância; Adaptação materna; Alergia respiratória. 


\section{Abstract}

Soto, Ramilda Fontan; Garcia, Cláudia Amorim. The psychosomatic at early infancy: Winnicott's contribution for a study of respiratory allergies. Rio de Janeiro, 2006. 230p. Doutorado thesis - Departamento de Psicologia, Pontifícia Universidade Católica do Rio de Janeiro.

The objective of the present thesis was to contribute to the understanding of psychosomatics manifestations in infancy, exemplified by respiratory allergic diseases. Winnicott's theory about the primitive emotional development was used as the main theoretical tool. At first we discussed the contributions of psychoanalytic psychosomatic authors, beginning with Pierre Marty's theoretical model to the literature concerning infancy, and also Winnicott's concepts about mother-child relationship. The research used the Winnicott's conception of primary maternal preoccupation, focusing the mother's active adaptation, and showed the existence of a relation between failures in the maternal adaptation and the child's psychosomatic allergic manifestation.

\section{Key words:}

Winnicott; Psychosomatic; Childhood; Mother adaptation; Respiratory allergy. 


\section{Sumário}

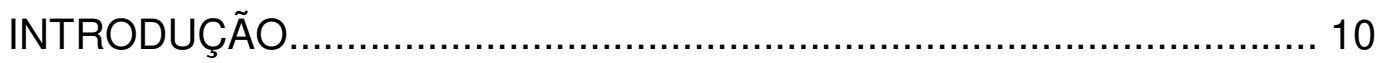

1. A CONSTRUÇÃO DO CAMPO PSICOSSOMÁTICO........................... 16

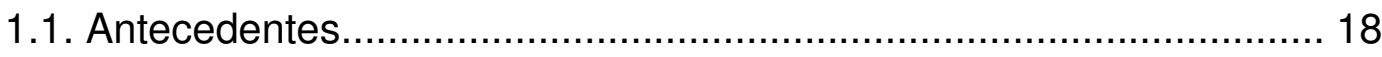

1.2. De Freud à Escola de Psicossomática de Paris................................ 24

1.2.1. As relações entre o psíquico e o somático na obra de Freud....... 25

1.2.2. As contribuições de Groddeck, Ferenczi e Alexander................... 34

1.2.2.1. Groddeck e o valor dos símbolos: a doença como linguagem.. 34

1.2.2.2. Ferenczi: o estudo das neuroses de doença............................ 43

1.2.2.3. Alexander: a inauguração da medicina psicossomática............ 47

1.2.3. A constituição da Escola de Psicossomática de Paris................... 51

1.3. O modelo psicossomático de Pierre Marty...................................... 56

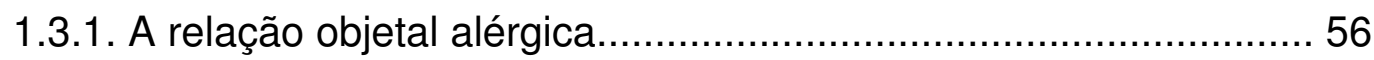

1.3.2. Os processos de somatização.................................................... 60

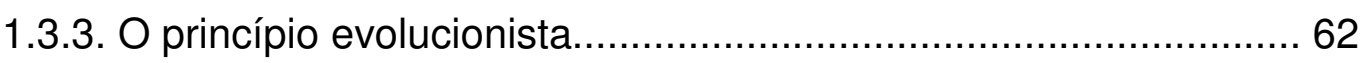

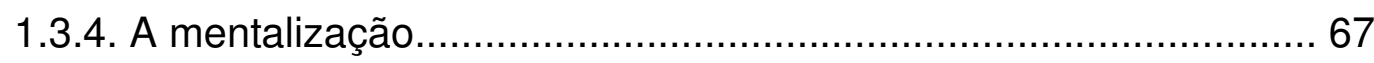

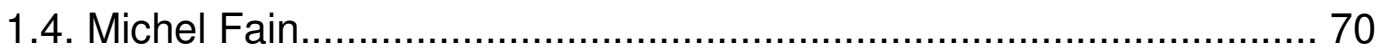

2. A PSICOSSOMÁTICA DA INFÂNCIA................................................ 73

2.1. Um estudo precursor: René Spitz e a patologia das relações objetais no primeiro ano de vida............................................................. 74

2.1.1. Os estados de carência e privação afetiva.................................... 75

2.1.2. A gênese das relações objetais.....................................................79 
2.1.3. Os desvios das relações objetais. .82

2.2. Contribuições dos estudos sobre as interações precoces............... 86

2.3. O estudo da psicossomática psicanalítica do bebê........................ 91

2.3.1. Leon Kreisler e a interação precoce de risco psicossomático...... 98

2.3.2. Rosine Debray.......................................................... 101

2.4. A psicossomática dos distúrbios alérgicos respiratórios do bebê... 104

2.5. Do pulsional ao relacional: uma mudança possível na abordagem dos distúrbios psicossomáticos da infância

3. WINNICOTT E A CONQUISTA DA UNIDADE PSICOSSOMÁTICA..120

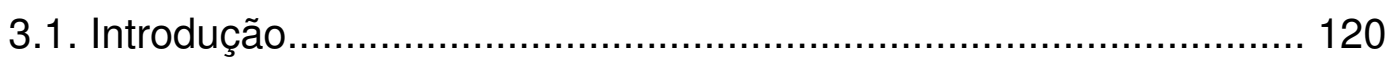

3.2. A relação mãe-bebê anterior ao complexo de Édipo: uma mudança

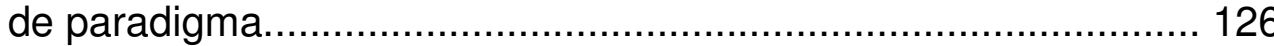

3.3. Através da pediatria à psicanálise: um caminho de mão-dupla entre a prática e a teoria............................................................ 132

3.3.1. O início da trajetória..................................................... 132

3.3.2. O percurso no campo da psicanálise.................................... 140

3.4. O cuidado ambiental suficientemente bom................................ 143

3.5. O corpo nos primórdios do funcionamento psíquico.................... 148

3.5.1. A experiência do nascimento............................................ 156

3.5.2. A amamentação......................................................... 160

3.5.3. Integração e personalização: as tarefas do bebê...................... 165

3.6. O transtorno psicossomático.............................................. 169

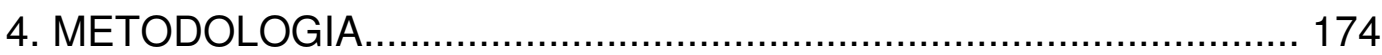

4.1. Descrição da pesquisa................................................... 175

4.2. Roteiro das entrevistas.................................................. 177 
4.3. Considerações metodológicas............................................ 182

4.4. Análise das entrevistas................................................... 189

4.5. Interpretação dos resultados............................................. 209

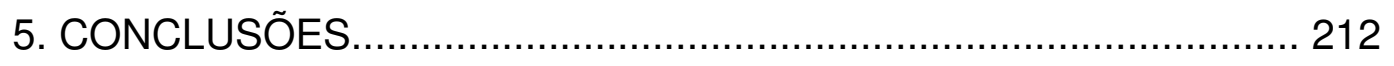

6. REFERÊNCIAS BIBLIOGRÁFICAS ........................................ 216

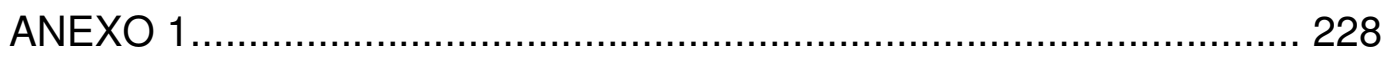

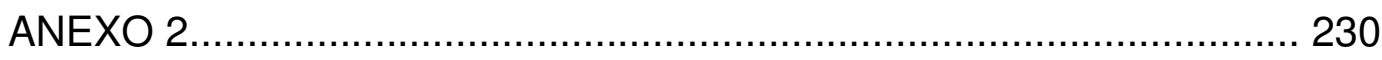

